\title{
Impact of Artificial Intelligence on Vietnam Commercial Bank Operations
}

\author{
My Sang, Tang ${ }^{1}$ Hung Nguyen Tien ${ }^{2}$ \\ ${ }^{1,2}$ Faculty of Economics, University of Finance and Economics, Ho Chi Minh City, Viet Nam \\ *Corresponding author: My Sang, Tang tangmysangk11@gmail.com
}

Received 25 June 2020;

Accepted 01 July 2020;

Published 10 July 2020;

\begin{abstract}
Through secondary data, the research study about the impact of artificial intelligence (AI) on commercial bank operations. Research results show that $\mathrm{AI}$ is being applied in the banking industry with many different applications such as Chatbot, risk assessment, anti-money laundering, fraud detection, and algorithmic... The application of AI in the banking industry is changing day by day, but the trend of AI application of the bank focuses on three goals that affect the bank's operations. The impact of AI on banking operations including the impact on customer experience, the impact on the bank's cost and performance, the impact on risk management, and the impact on bank compliance.
\end{abstract}

Keywords: Artificial intelligence, AI, commercial bank, fintech, bank performance

\section{Introduction}

Commercial bank is one of the most important financial institutions in the economy, its operations have a strong impact on other entities in the economy, so the banking industry's activities always receive the attention of the society. Experiencing three major scientific and technological revolutions including the first industrial revolution (1784), the second industrial revolution (1870), the third industrial revolution (1969), the commercial bank has made important steps from manual data processing, storing paper book systems and manual jobs, these jobs have gradually been processed by computers via the internet. In the context of the digital transformation of the industrial revolution 4.0, the financial market in general, and the banking industry, in particular, have been changing dramatically.

The 4.0 technology revolution is a blend of physical, digital and biological technologies (Schwab, K. 2016). Basically, this revolution will change the current production base on the application of new technologies such as digitization, robotization, $\mathrm{AI}$, and the Internet of Things (IoT). The innovation in digital technology has taken the economy and business forms of businesses to a new step, marking the advent of e-commerce, cashless payments, and a lot of new services that are born, better support, replace human work.

Commercial bank always create huge data blocks from structured data such as transaction history, customer records to unstructured data such as customer activity on the website, application of mobile banking (mobile banking), electronic banking (internet banking), application of AI technology is an indispensable trend (Srivastava, 2015). AI applications in the banking industry today include automation in customer services, personalized customer service experience, enhanced security, sample recognition, and fraud detection. optimize process, participate in the credit risk management process, analyze customer feedback ...(Kaya, 2019; Vives, 2017)

In the context of AI growing strongly, the commercial bank system receives many benefits. AI not only help renewing services, improving internal management quality but also ensures business efficiency with the most optimal risks and costs, helping sustainable development of banks (Alzaidi, 2018). Since then, these technologies have gradually become an important and core resource that creates a competitive advantage in any organization, especially when the grasp of customer needs is increasingly complex (Kaya, 2019)

Grasping this importance, many Vietnam commercial banks have been gradually applying these technologies into their operations. Data of Vietnam State Bank shows that $94 \%$ of banks have initially implemented or are studying and building a digital conversion strategy, of which $59 \%$ of banks have started to implement digital transformation in practice. The majority of Vietnam banks have implemented digital banks at the conversion level in terms of communication channels and processes, while the conversion to new data platforms has been studied and implemented in some pioneering banks (Khanh Ly, 2019).

However, Vietnam commercial bank faces many challenges in terms of facilitating the legal framework, ensuring network security and data security, raising customers' awareness and skills, choosing an effective investment in IT infrastructure to ensure successful digital transformation in Vietnam. There are also many difficulties in the implementation process. From these urgent issues, this study wants to identify the impact of AI on bank operations to make policy implications for the Vietnam commercial bank system transition.

\section{AI and AI development}


AI is a broad concept, related to the advancements of intelligent computers. There are many different terms related to AI such as image recognition, natural language processing (NLP), cognitive computing, intelligence boosters, and enhanced intelligence (Yaninen, 2017).

AI was formed and developed with the development of Fintech. Up to now, the world has gone through 4 stages of technological innovation. The first revolution occurred in 1784, when the world's first steam engine was introduced. The second phase of electricity was established. The third was in 1969 when information technology was introduced to the world, and the fourth was the AI revolution, in which humans are currently witnessing, rooted in Robust automation and worldwide connectivity using AI (Jenner, 2017).

The first industrial revolution used water and steam capacity to automate production. The second uses electrical capacity for largescale production. The third uses electronics and data innovation to computerize. The fourth industrial revolution is further expanding the third technological revolution, which is the computer revolution taking place since the middle of the last century. The fourth technological revolution is considered to be a combination of advances in blurring the boundaries between physical, computer and biological circles (Schwab, 2016).

The term "AI" was born in 1956 by computer scientist John McCarthy at the Dartmouth Conference. The original goal of AI was to perform alternative tasks for humans to serve humans. However, this goal was not achieved until 1973, at the British scientific research council, the birth of AI in the previous period was completely failed due to ideas that could not be implemented (Gokul, 2018). In 1990, great advances in AI were widely applied. One of the first products to mark AI achievements was IBM's BlueChip chess machine, produced in 1991. In 2017, Google's Go game, DeepMind's AlphaGo, hit marks a new step for AI to handle much more complex thinking. This event is considered a landmark achievement in the development of AI. Currently, many A.I. expert types, like AlphaGo. The 21 st century also sees many powerful AI commercial applications, when solutions such as image recognition, sound recognition, natural language processing help people handle repetitive tasks.

The purpose of AI is to develop an intelligent and autonomous system. The AI has a subset of MLS that allow computers to learn on their own and improve their understanding without specific programming. There are two methods of operating AI, one based on symbols and the other based on data. For the database side called machine learning (ML), it is necessary to provide the machine with a lot of data before it can learn. The machine can learn in more dimensions. The machine can look at a lot of height data and identify patterns. When these models are learned, machine learning can make predictions of problems even inaccessible to humans (Takyar, 2018).

Artificial intelligence is the activity that makes machines intelligent, and intelligence is the quality that allows an entity to function appropriately and foresight in its environment. Specifically, when the computer uses algorithms to complete the assigned tasks, this action is called the computer using AI to solve the problem. To accomplish this task, AI combines a group of technologies (computer vision, natural language, virtual assistants, automation and advanced machine learning) that allow machines to simulate sensory, understand and act like humans (Nilsson, 2009)

\section{Application of AI in the banking industry}

$\mathrm{AI}$ is applied in the banking industry with many different features such as Chatbot, credit risk assessment, management assistance, anti-money laundering, fraud detection, and Algorithmic.

\subsection{Chatbot and invisible assistant}

Chatbot is built based on a natural language processor and uses chatlog. These assistants then automatically understand the terminology of financial services and customer requests for money. Over time, the team of experts in algorithms, platforms, and customer service has built a rich and multi-layered volume of chatbots to enhance chatbot functionality.

Chatbot brings many benefits in the business of the banking industry, the main benefits can be listed including relationship improvement, building, and promoting more utilities from mobile banks. Enhance customer experience through interactive features like people. Retaining customer knowledge, when Chatbot talks with customers, banks will build a question resource, and Chatbot's ability to respond will be higher with answering more complex questions. Reduce costs and maintain, improve customer service levels as the number of customers and businesses is increasing. Job satisfaction increases by allowing customer service staff to focus on higher-value tasks.

\subsection{Risk assessment}

\subsubsection{Credit risk}

The introduction of credit cards can be considered a remarkable improvement in the services provided by the banking industry. Customers who want to use this card must be granted a credit line based on their financial capacity and potential credit risk.

The basis for credit appraisal for customers is the historical data source, but the credit rating model is based on credit risk and historical database in the traditional way. To improve expenditure, non-bank lenders, like fintech companies, are using AI solutions, which pushes up the competition of the financial industry.

The basis for credit appraisal is the historical data source, but the credit rating model is based on credit risk and historical database in the traditional way which is inefficiencies. To improve this, non-bank lenders, like fintech companies, are using AI solutions, which pushes up the competition of the financial industry.

In the process of credit risk managing, the most important step is identifying credit risk. The most commonly used traditional method to quantify credit risk is credit scoring analysis, developed by Edward Altman (Altman, 1968). Through AI, this method is now more advanced. AI support for banks quantitative and qualitative analysis of customer data.

\subsubsection{Operational risks}

One area of operational risk where AI can have a significant impact is the identification of fraudulent actions. Fraud reduction is becoming a top priority for banks. However, traditional methods of fraud identification, such as using rules tools written by humans, account for only a small percentage of fraud cases. The large group of frauds required by humans leads to many traditional fraud detection measures. Banks are using AI to improve their predictions, identify real cases, and reduce false in forecasts. In fact, AI applications have been identified as the most valuable fraud detection method in banks (Joshi, 2019).

\subsubsection{Liquidity risk}

An important task involving liquidity management is cash flow forecasting. The analytical power of AI can identify and predict future results arising from current transaction data affecting the 
liquidity of a bank. AI then activates automatic response protocols to help resolve such events (Deloitte, 2018)

\subsection{Support management and cross-selling}

Cross-selling has become one of the main sources of income for banks. Because the bank has information about customers such as financial situation, historical spending behavior, and investment portfolio, it is possible to develop these cross-selling products. AI can help banks through a digital campaign, particularly digital marketing groups that will conduct product exclusion, leveraging customer relationship management lists to find the best products. In fact, customers can meet many different products, this can lead to confusion for banks in advising the best products for customers. AI helps banks solve this problem by finding the best product that matches the available data.

Based on data from social media activities, AI helps improve understanding and learning over a period of time. The bank can then identify patterns and make connections to previous insights to form new insights and take action.

This feature of AI brings many values to banks such as bringing new products to existing customers, making individualized customer decisions. Improve the customer experience through promoting new sales channels. Increase revenue for banks and improve customer retention.

\subsection{Algorithmic}

Financial institutions, especially hedge funds and proprietary traders, have used algorithmic, or black-box trading, for trading. This is the use of mathematical models designed to automatically react to changing market conditions in real-time, opening and closing positions according to predefined parameters without the intervention of humans. Algorithmic has been widely applied by large financial institutions such as investment banks and investment funds, helping to perform faster at the best price, which is beneficial for the company and customers. The advantages of these transactions are increased accuracy and fewer errors, automatic checking of multiple market conditions at the same time, fewer errors for psychological or emotional causes.

\section{The impact of AI on banking operations}

\subsection{Impact on customer experience}

The financial services industry has changed significantly to meet customer expectations. In the past, services supply for customer was limited to traditional products and services, customers now expect more innovative, more relevant services for the digital age. Traditional banks started to implement digital transformation, applying AI systems to gain insight into their customers, their needs and preferences, giving them the ability to better adjust their services. service and increase the ability to attract new customers. Banks use AI to tailor products and ads based on demand and behavior by combining information from transaction history, prior requests, geolocation, and search history of customers. and even social media sites.

AI serves with the best bank services by understanding customer requirements. AI can analyze different types of data and get insights into customer behaviors and interests. Historical data plays an indispensable role in finding the buying patterns of customers needed to provide the expected bank products and services. Most traditional banks still have main transaction relations with their customers by providing deposit and payment services. By holding the information of an individual customer and using AI techniques to analyze this information, banks can make recommendations for financial products tailored to each customer. It can be said that by promoting "personalization", AI is strengthening customer relationships by using natural language as a way that customers can interact.

\subsection{Impact on the cost and performance of banks}

AI is applied to eliminate most of the time-consuming and errorprone jobs associated with importing customer data from contracts, forms, and other sources. Improved handwriting recognition, natural language processing, and other technologies, combined with intelligent process automation tools, are being increasingly used in office operations for handling bank workflows. The number of personnel handling operations can be reduced. In addition, by replacing human processes with AI-based automation, banks can impose regulatory and regulatory controls that were previously impossible. By replacing people with smart, automated assistants, banks can focus human resources on higher-value tasks such as providing new services to customers or improving customer satisfaction. customer...

Previously, banks reduced costs through key activities. When technology began to develop, AI gradually improved, banks reduced operational costs by reducing the time and resources devoted to the increasing number of processes. In addition, banks often rely on internal units or outside professional legal services firms to determine the applicability of regulations and determine the gap between legal requirements and the books and internal procedures.

However, some banks are currently leveraging AI to do this work, as well as to check ongoing regulatory compliance. In addition, AI also affects the processing time of banks, especially improving the processing time for individual customers. Through the use of automated processing, the AI extracts key data to process loan applications in seconds. For lending operations, the traditional method of reading documents manually, but by using optical character recognition (OCR) physical documents can be digitized using AI. The price of alternative data for humans, thereby reducing costs, increasing operational efficiency for banks.

\subsection{Impact on bank risk management}

AI helps banks make credit and lending decisions more profitable and safer. Currently, many banks are still restricted from using credit scores, credit history, customer references, and banking transactions to determine whether an individual or company is trustworthy. AI helps banks improve these issues. In addition to using available data, AI-based loan decision systems can also look at behavior and patterns, to determine a customer's credit history. AI applications can analyze and organize large amounts of unstructured data to gain insights, to help analyze bank credit risk better. These effects are particularly useful to the chief financial officers, credit risk management directors and chief compliance directors, bringing added value to the board, senior management and regulators.

\subsection{Impact on bank compliance activities}

Banking activities must comply with a lot of regulations to ensure the prevention of money laundering from customers and information security. Compliance with bank regulations will incur significant costs, banks can use smart AI assistants, always support transactions, track customer behavior and check and record. Back information for compliance systems to have different regulatory ways. In addition, by considering customer behaviors and models instead of specific rules, AI-based systems can help banks comply with regulations while minimizing common risks. 


\section{Methodology}

The research uses qualitative methods to study the impact of AI on the operation of the Vietnam commercial bank system. The methods of interviewing, analyzing documents, and secondary data were selected and used to conduct research. The primary data was taken through a survey of 60 commercial bank leaders of selected commercial banks.

\section{Analysis and Interpretation}

To assess the impact of AI on the commercial bank operations, the researchers conducted a survey of some administrators of commercial banks in HoChiMinh City. The number of surveys issued is 60 , the result received is 55 , provides much useful information.

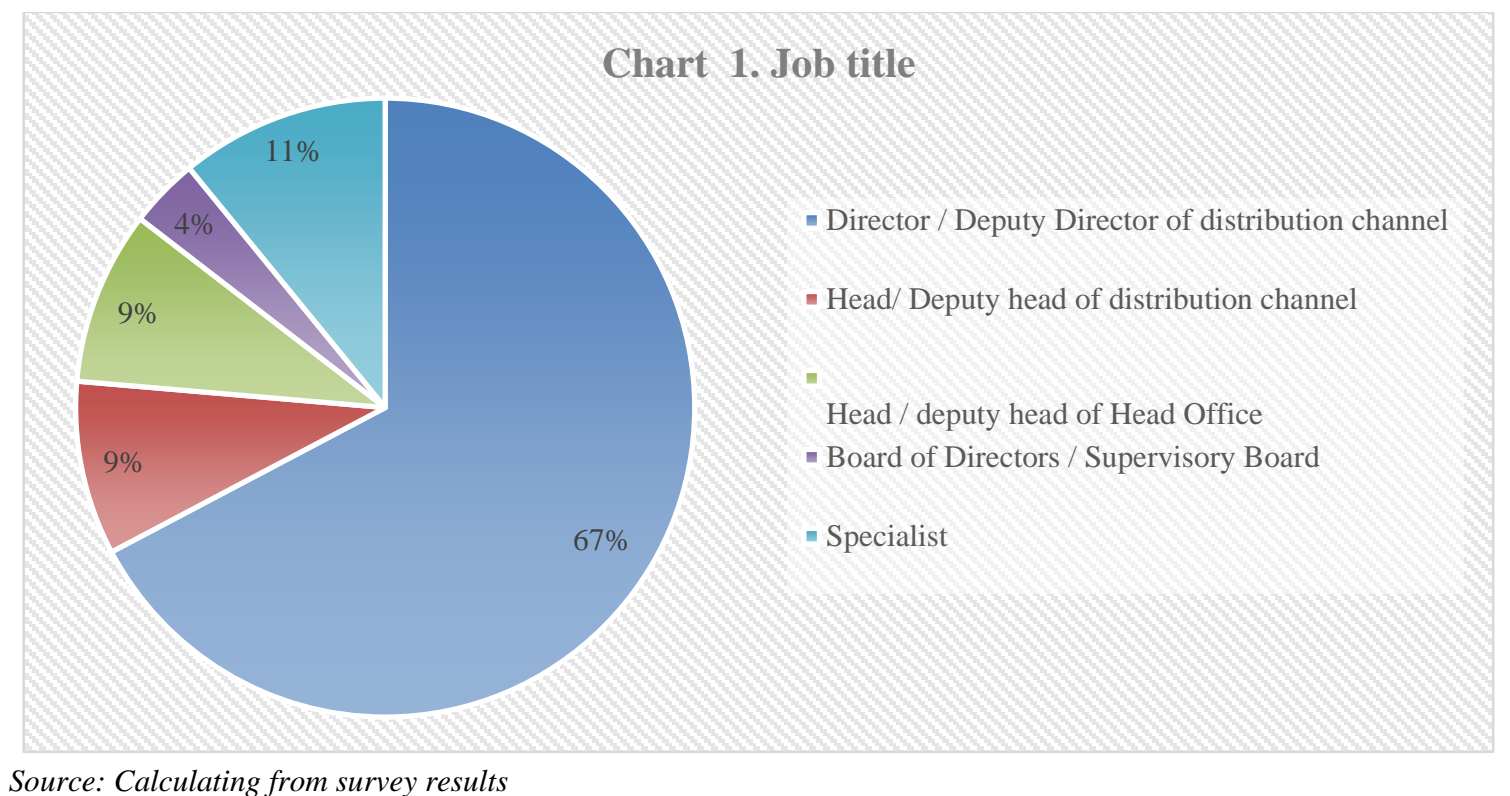

Source: Calculating from survey results

The information in Chart 1 shows that nearly $90 \%$ of respondents holding important management positions in the bank, from senior to middle managers of commercial banks, so the answers to the survey contents can be trusted.

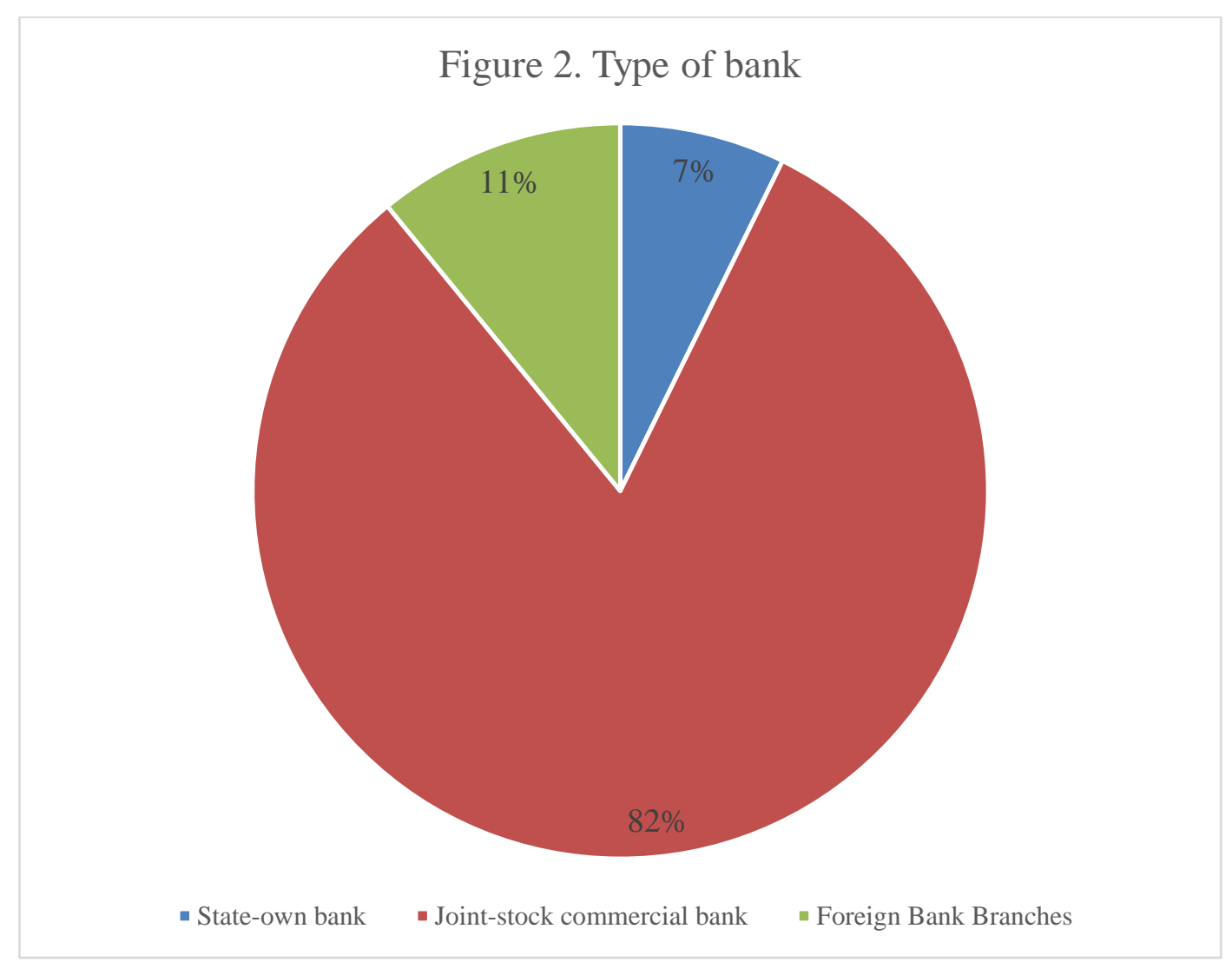

Source: Calculating from survey results

Chart 2 shows that about $80 \%$ of the sample is collected from commercial banks, because the number of joint-stock commercial banks accounts for a large proportion in the forms of commercial banks operating in Vietnam. The age of the surveyors above 31 accounted for $90 \%$ of the sample, of which over 40 years old accounted for $57 \%$ (chart 3 ). 


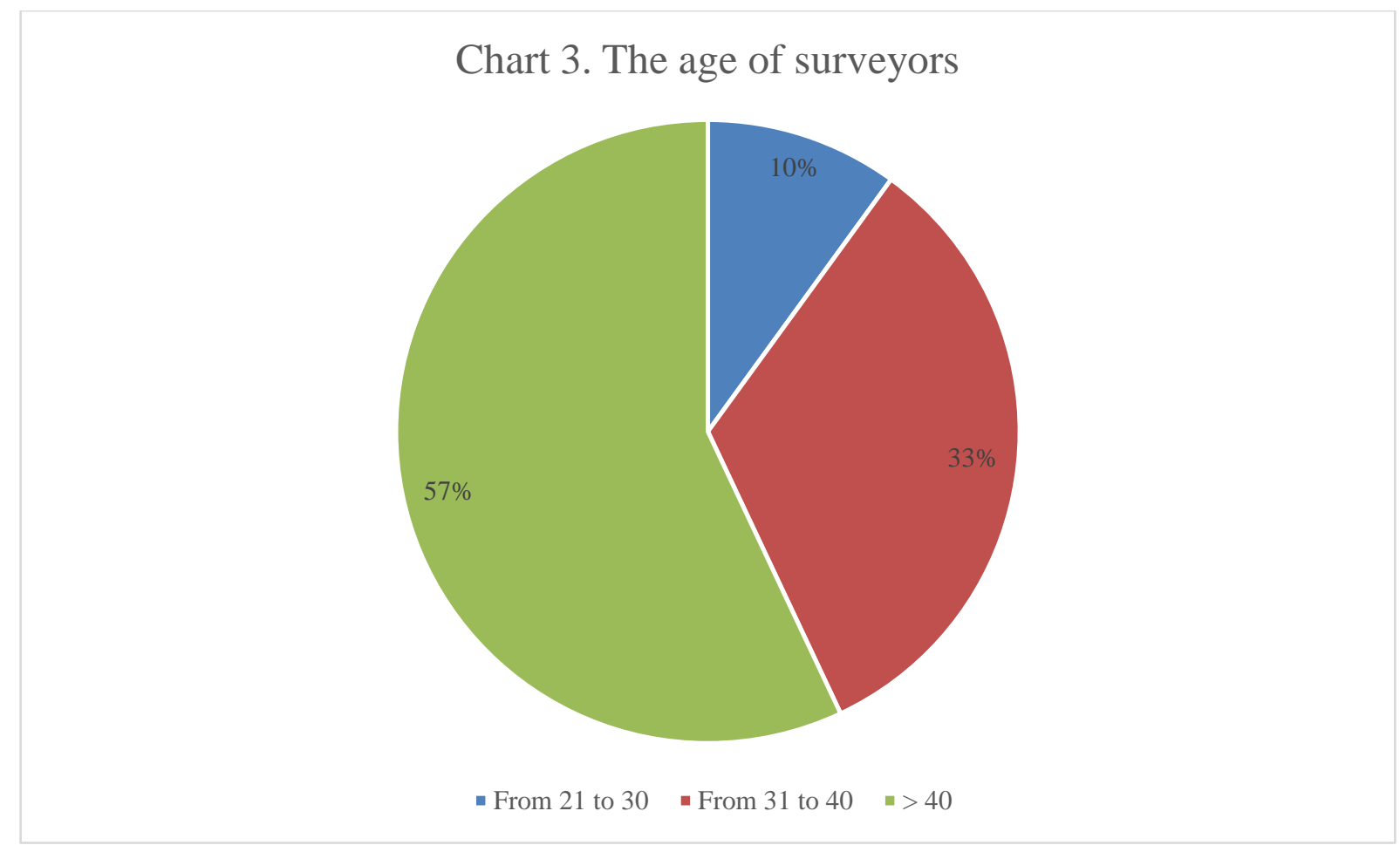

Source: Calculating from survey results

This age was sufficiently accurate and wise to perceive the problem. The number of working years of the sample is mainly from 5 to 10 years, the number of working years over 10 years accounts for $39 \%$ of the sample. The more years the surveyors work, the more experience the surveyors will have, the more reliable the surveyor judgments will be (chart 4)

Chart 4. The number of years working in the bank

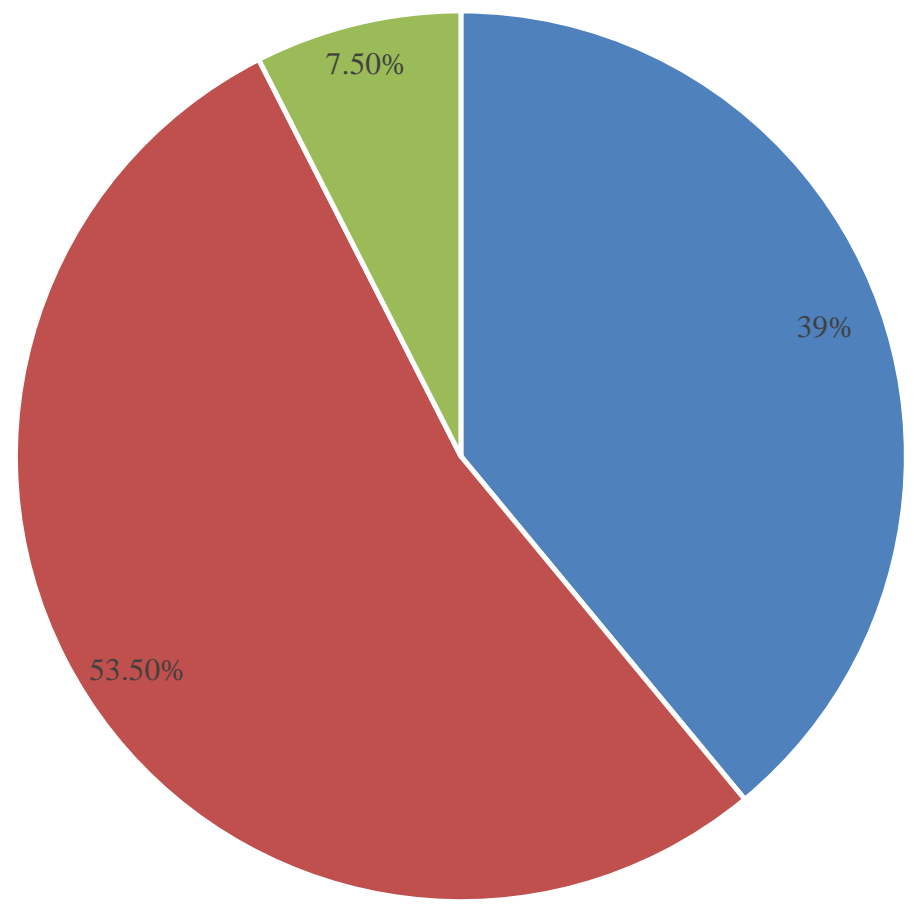

- $<5$ years - From 5 to 10 years $\quad>10$ years

Source: Calculating from survey results

The research results show that the level of access to the AI technology of the sample is accessible, of which most of surveyor have the knowledge of AI but not deep, up to $55 \%$ of the sample has begun to understand $\mathrm{AI}$ and only about $18 \%$ of samples have in-depth knowledge (Chart 5). 


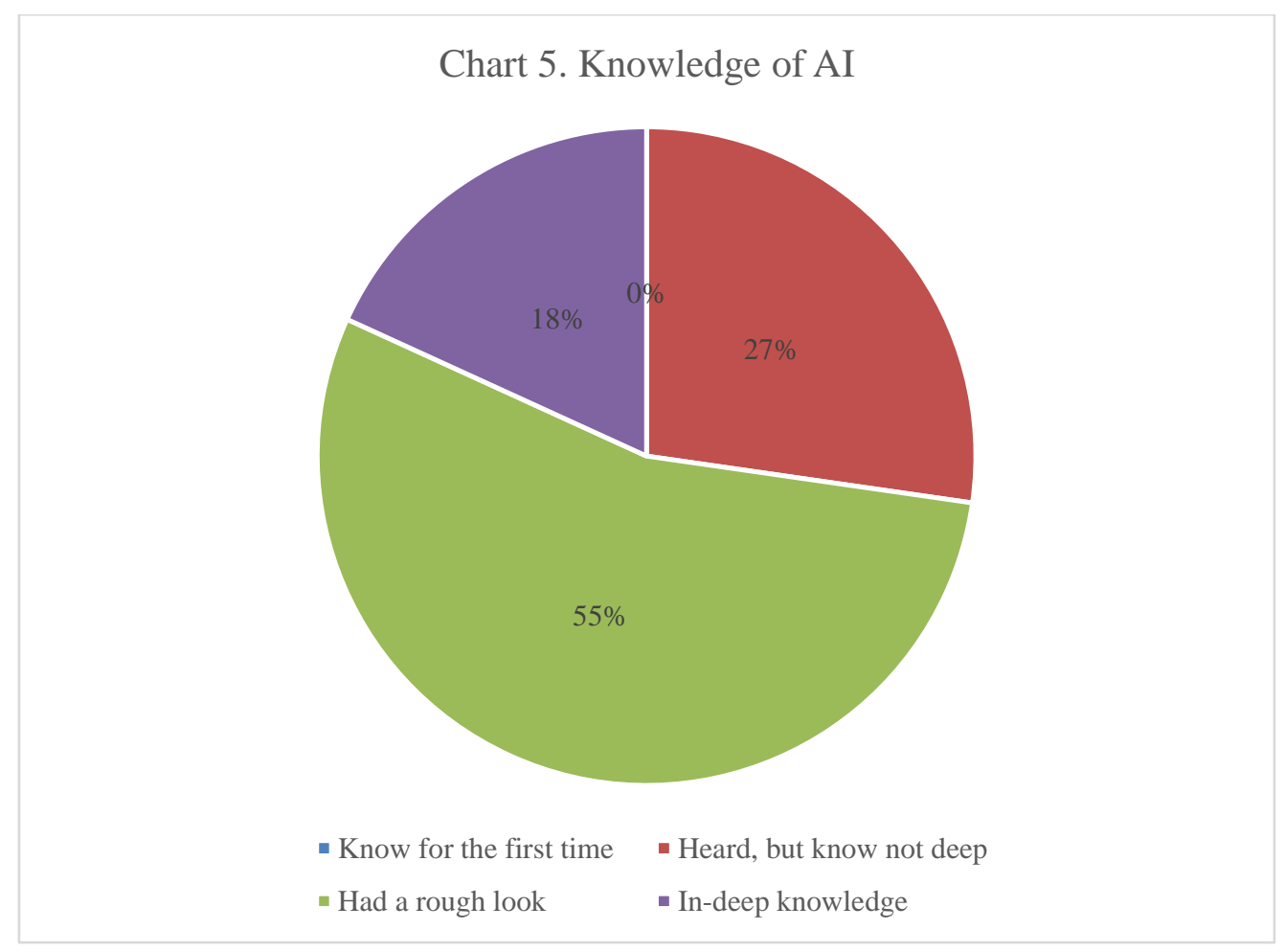

Source: Calculating from survey results

Vietnam commercial bank system is behind in technology but this bring many opportunities for banks, although some banks have just approached with the most elementary applications. The statistical sample shows that $91 \%$ of the survey samples indicate that banks have applied this technology (Chart 6).

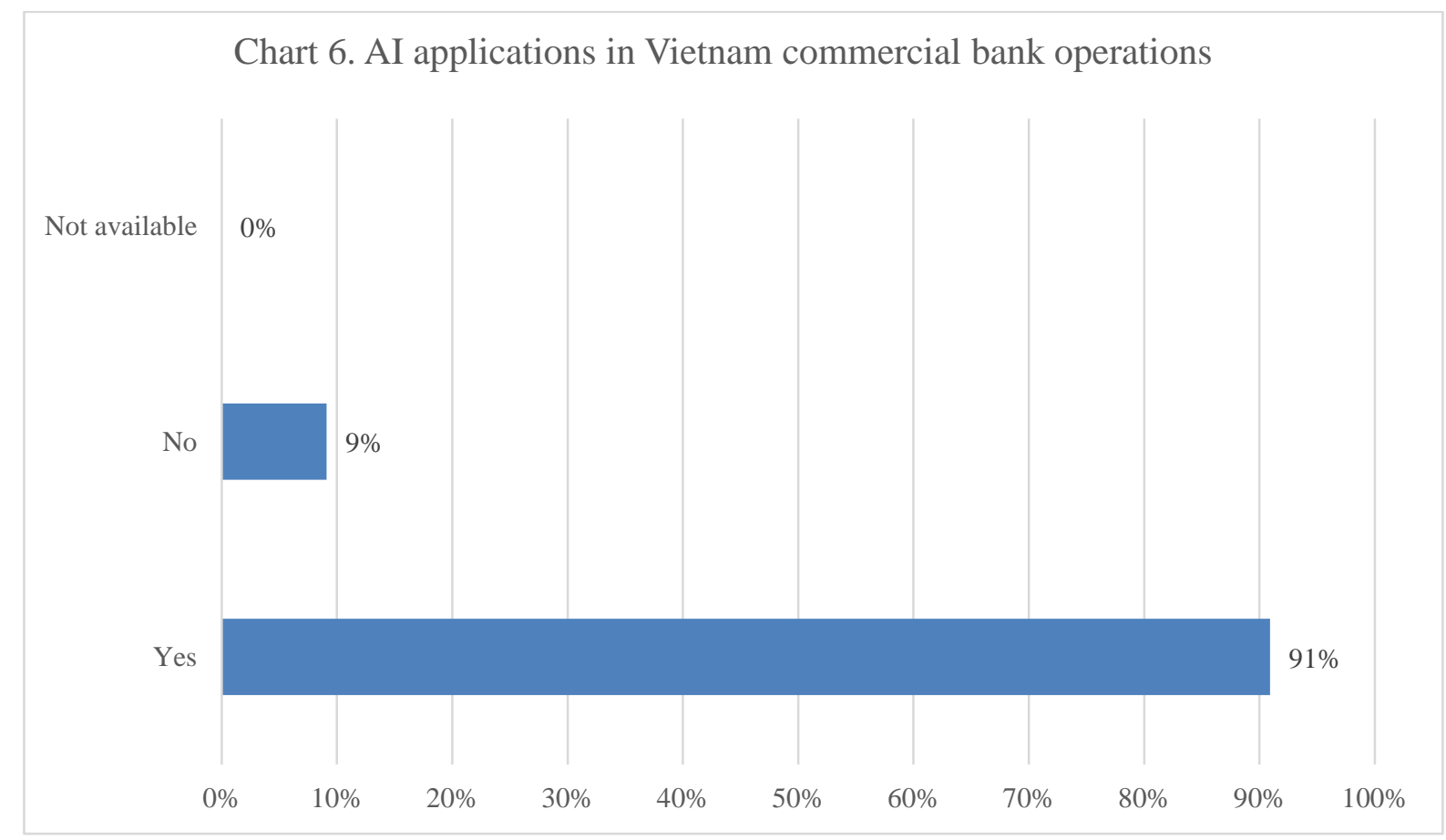

Source: Calculating from survey results

AI technology is mainly used by Vietnam commercial banks to support lending analysis, especially personal lending. Besides, this technology is also used to combat fraud because fraud brings a lot of risks to banks. When the needs of customers are increasing, banks with a huge customer base, the combination with other enterprises to cross-sell products helps banks increase revenue, big data technology also supports Vietnam commercial banks to implement this goal. AI helps to set up market segmentation, customer spending analysis, and marketing analysis. Application to set up the risk model accounted for the lowest density, the proportion of application is only about $10 \%$ (Figure 2.9). 


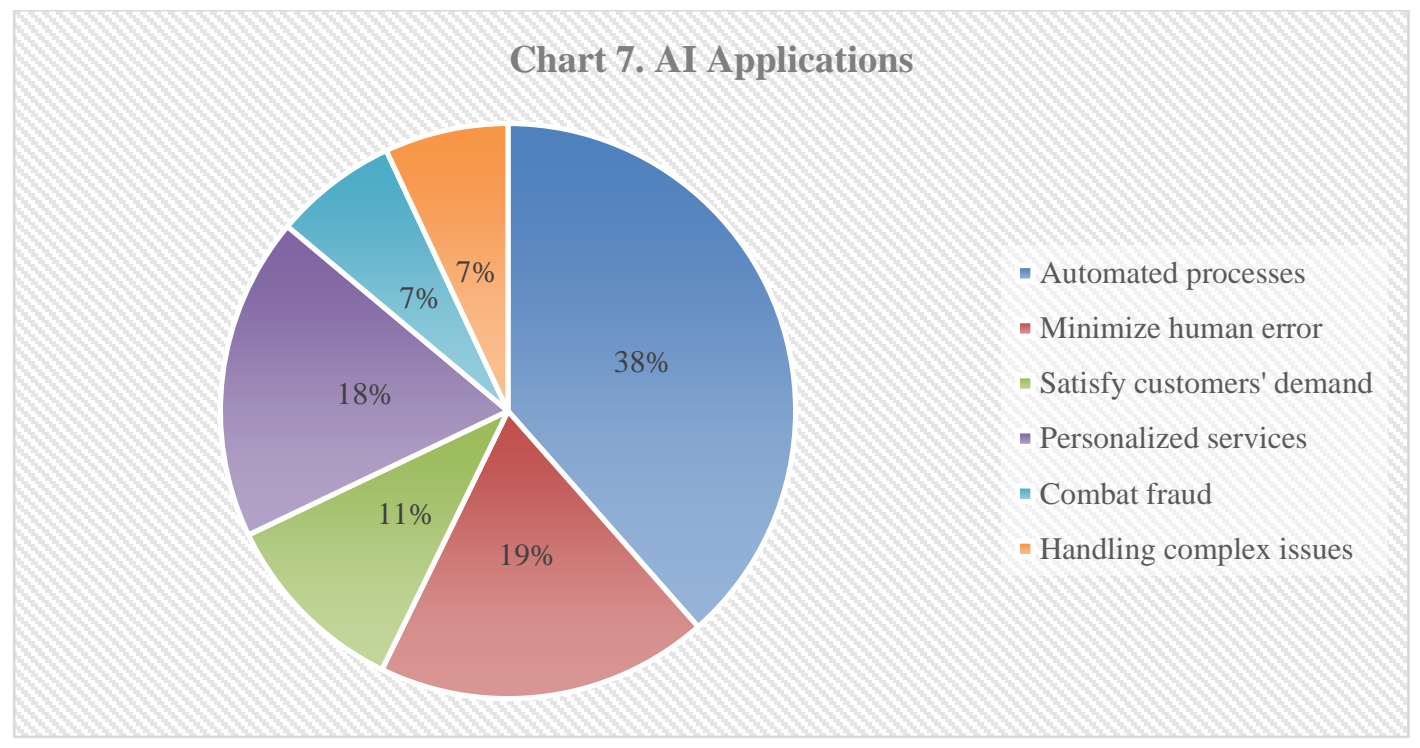

Source: Calculating from survey results

The application of AI technology has an impact on the operation of banks, more than half of the survey samples confirm that these technologies have an impact in which about 59\% think that there is a positive impact on the operations of banks, $29 \%$ said there is no positive impact, this may stem from the relatively high initial investment cost for technology, but this investment has long-term benefits for banks. When study about the impact of AI on the operations of Vietnam commercial banks, the impact on the complexity of products and services, fraud protection, and enhancing the performance of ATMs are most appreciated. Simplify the service to get a consensus rate of $67 \%$ of which $50 \%$ strongly agree. Anti-fraud rate is also very high, account for $75 \%$ of the total. Only the impact on customer satisfaction accounted for the lowest rate, only $19 \%$ of the total.

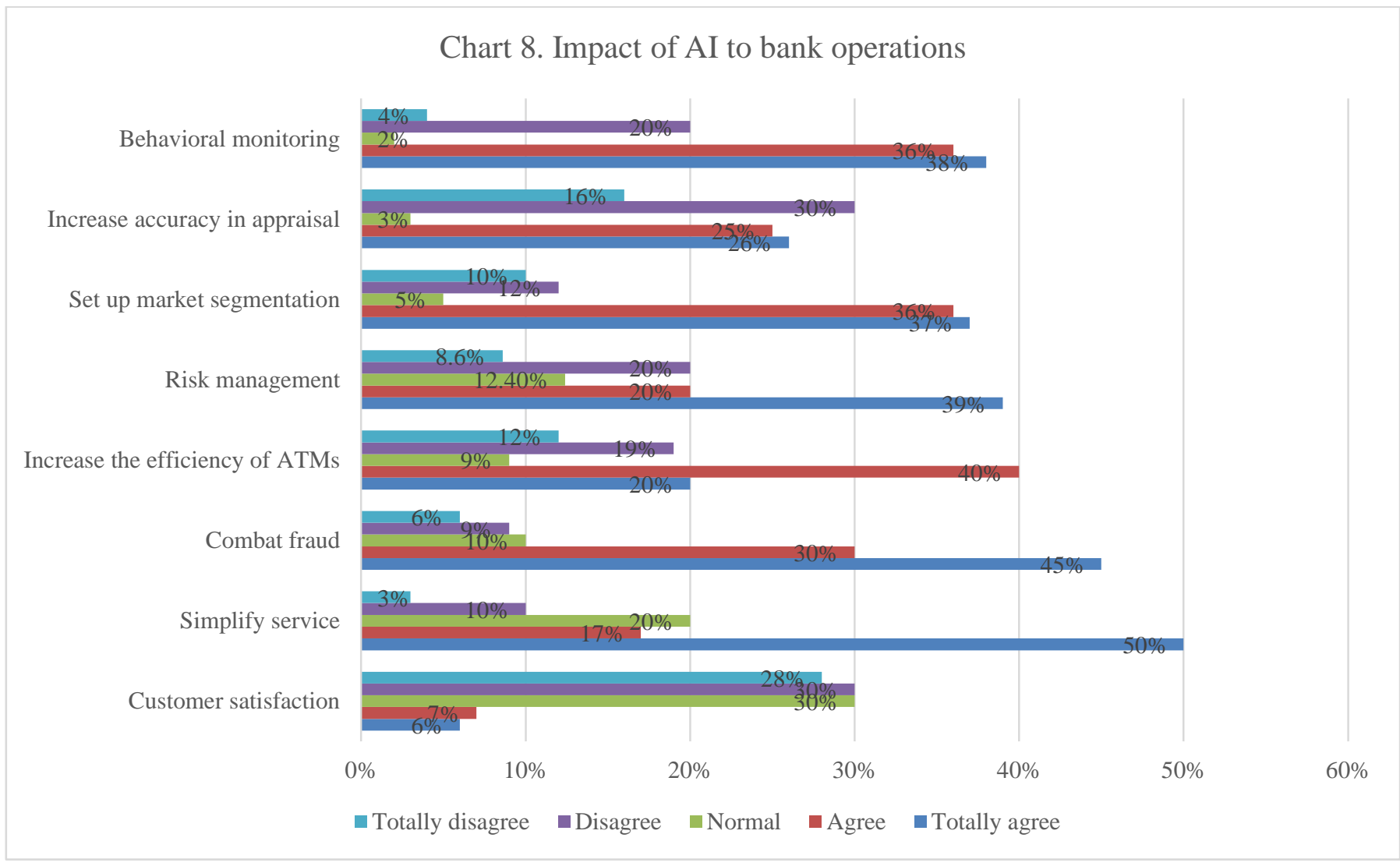

Source: Calculating from survey results

When study about the impact of AI on risk management, more than $50 \%$ of people agreed that these technologies have an impact on asset management, risk analysis, and the proposal of suitable products for customers through historical data (Chart 8). The impact of this technology on customer segmentation is more evident, the level of agreement is quite high, especially to help reduce transaction costs, understand customer behavior and help to automatically comply with bank processes.

\section{Findings and Discussions}

Research results of the impact of AI on Vietnam commercial bank operations show that AI is commonly used in Vietnam for three 
main purposes, including minimizing human errors, handling automatic submission, and support for personalized services. AI has an impact on bank operation and has a more positive impact than the negative impact, expressed by the impact of AI on the complexity of products and services, fraud protection, and enhancing the performance of the ATM machine is most appreciated. Besides, AI also has impacts on behavioral monitoring, customer partitioning, increased accuracy in credit appraisal, and credit risk governance of banks.

\section{Limitations}

Because the secondary data on AI in Vietnam is not transparent, the research paper cannot assess deeply the level of application of AI compared to other countries, thereby having a more objective view of the impact of AI to the operation of commercial banks.

\section{Data Availability}

All data generated and analyzed are available in this paper

\section{Conflicts of Interest}

The author(s) declare(s) that there is no conflict of interest regarding the publication of this paper.

\section{References}

[1] Altman, E.I., (1968), "Financial Ratios, Discriminant Analysis and the Prediction of Corporate Bankruptcy", The Journal of Finance, Vol. 23, No. 4, pp. 589-609.

[2] Alzaidi, A. A. (2018). Impact of Artificial Intelligence on Performance of Banking Industry in Middle East ocr. International Journal of Computer Science and Network Security, 18(10), 140-148.

[3] Deloitte. (2018). "AI and Risk Management"
[4] Jenner, G. (2017). AI-enabled world will change reality: airlines underestimating the likely future role of artificial intelligence in day-to-day operations might not only lose out on cost savings and other efficiencies, but also revenue opportunities. Flight airline business.

[5] Joshi, N. 2019. 7 Types of artificial intelligence. Available:

https://www.forbes.com/sites/cognitiveworld/2019/06/19 77-types-of-artificial intelligence/\#103c8bcb233e. Accessed 3 July 2019

[6] Kaya, O., Schildbach, J., AG, D. B., \& Schneider, S. (2019). Artificial intelligence in banking. Artificial intelligence.

[7] Klaus Schwab (2016), The Fourth Industrial Revolution: what it means, how to respond, https://www.weforum.org/agenda/2016/01/the-fourthindustrial-revolution-what-it-means-and-how-torespond/, access in 22/6/2020

[8] Gokul, B. (2018). Artificial Intelligence in Financial Services. Sansmaran Research Journal, 8(1), 3-5.

[9] Nilsson, N. J. (2009). The quest for artificial intelligence. Cambridge University Press

[10] Srivastava, U., \& Gopalkrishnan, S. (2015). Impact of big data analytics on banking sector: Learning for Indian banks. Procedia Computer Science, 50, 643-652

[11] Takyar A. 2018. What is Artificial Intelligence? Understand artificial intelligence in 5 minutes. Available: https://www.leewayhertz.com/what-is-artificialintelligence-understand-ai-in-5-minutes/. Accessed 10 March 2019.

[12] Yaninen, D. 2017. Artificial Intelligence and the Accounting Profession in 2030. Available: https://cpapng.org.pg/data/documents/CPA-PresentationArtificial-Intelligence-and-the AccountingProfession-in2030_1.pdf. Accessed 20 June 2019.

[13] Vives, X. (2017). The impact of FinTech on banking. European Economy, (2), 97-105. 